\title{
What are the benefits of routine breast cancer follow-up?
}

\author{
S. Morris, A.P. Corder and I. Taylor \\ University Surgical Unit, Southampton University Hospitals, Level F, Southampton General Hospital, \\ Tremona Road, Southampton SO9 4XY, UK.
}

Summary: The value of follow-up after potentially curative treatment of breast cancer remains controversial. Recurrence-free women $(n=402)$ attending a breast clinic over a 3 month period were studied. The women attended 423 appointments, 412 of which were routine. Eleven were requested by the patient or general practitioner (interval appointments). All 11 interval and 19 of the routine appointments resulted in investigations for possible recurrence. Three $(27 \%)$ interval appointments and four (1\%) routine appointments resulted in the diagnosis of a recurrence $\left(P<10^{-5}\right)$.

The attitudes of 285 patients to follow-up were investigated by questionnaire. Two hundred and twenty-three (78\%) questionnaires were completed. Regular follow-up in the breast clinic was preferred to attendence only when symptomatic by $190(85 \%)$ women and $169(76 \%)$ preferred regular breast clinic visits to general practitioner follow-up. Most women $(n=174)(81 \%)$ said they felt reassured and less anxious having attended the breast clinic. Routine follow-up after potentially curative treatment of breast cancer is inefficient in the detection of recurrence. It is, however, highly rated for providing reassurance and reducing anxiety. Reassurance rather than detection of recurrence may be the most important function of the breast cancer follow-up clinic.

\section{Introduction}

Follow-up is standard practice in the aftercare of patients having surgical treatment for breast cancer. Very few recurrences are, however, potentially curable and it is probable that this practice has little effect on the subsequent course of the disease. ${ }^{1}$ It is likely, though, that routine follow-up provides a framework for psychological support and is popular for this reason., ${ }^{2,3}$

In this study, the effectiveness of follow-up in the detection of recurrence has been assessed. Also, patients' attitudes and the degree of social and domestic disruption caused by the follow-up process have been measured using a questionnaire.

\section{Patients and methods}

All patients receiving potentially curative treatment for breast cancer from one unit are followedup in two special weekly clinics. Routine follow-up appointments are given 3 monthly for the first year, 4 monthly for the next 2 years, 6 monthly for the next 2 years, and then annually for the next 5 years. An option of discharge from the clinic is given at 10 years.

Correspondence: A.P. Corder, M.S., F.R.C.S. Accepted: 15 April 1992
An audit of these clinics was performed over month period. All patients who had receivedo surgical treatment with or without adjuvant therapy and were free of recurrence at the start of the study were included. All suspected and confirm-응 ed recurrences during the study period were noted $\varrho$ as was the method of presentation. Appointments $\overrightarrow{\vec{O}}$ initiated by patients or their general practitioners between routine visits were termed 'interval'.

Patients were asked to complete questionnaires: during the clinic. The questions are shown in Tableo I(a). Broadly, they deal with the effect of clinicattendance on social and domestic factors, atti- $\frac{-}{3}$ tudes to breast self-examination and with attitudesto the follow-up clinic.

Results

Four hundred and two study patients attended during the 3 month period. The median age of the women was 62 (range 23-89) years and the median duration of follow-up was 2 years (range 1 month- $-\omega$ 17 years). The treatments and histological diag noses are shown in Tables II and III. Two hundred을 and forty-one patients had negative axillary nodes, 103 patients had positive nodes and, in 48 patients, the nodal status was unknown.

The 402 patients attended 423 appointments

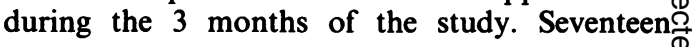


Table I

$\begin{array}{ll}\text { (a) Questionnaire } & \text { (b) Results* }\end{array}$

1. Did you have to take time off work to come to the clinic? Yes $49(22 \%)$

No $173(78 \%)$

2. Did you have to make special domestic arrangements to

Yes $27(12 \%)$ come to the clinic?

No $195(88 \%)$

3. How far did you have to travel?

1-5 miles

6-10 miles

11-20 miles

$115(52 \%)$

$61(27 \%)$

$34(15 \%)$

21-30 miles

$11(5 \%)$

31-50 miles

$1(0.5 \%)$

4. How did you travel?

Your own transport $139(64 \%)$

Public transport

$65(30 \%)$

Hospital transport

$4(2 \%)$

Other

$9(4 \%)$

5. For what reason have you been asked to attend this

clinic?

For a check-up

$209(96 \%)$

For tests

$1(0.5 \%)$

For results

$7(3.5 \%)$

Do not know

$0 \quad(0 \%)$

6. Have you been taught how to examine your breast area?

7. Approximately, how often do you examine your breast area?

More than once a month

Once a month

$75(35 \%)$

$85(39 \%)$

$35(39 \%)$

Less than once a month

$21(10 \%)$

8. If you were taught to examine your breast area, would you prefer to:

Report to the clinic only if you had any worries?

Continued to see us for follow-up as you do now?

$30(15 \%)$

$168(85 \%)$

9. If you are having long-term follow-up, would you prefer to:

Be seen at the hospital breast clinic (as now)?

Be seen by your general practitioner?

10. When you attend the clinic do you feel:

Reassured and less anxious?

No different?

More concerned and anxious?

$8(4 \%)$

11. Would you find it helpful to be given more information Yes $142(67 \%)$ about breast disease?

No $69(33 \%)$

*Not all women answered all questions. Percentages refer to those responding to individual questions.

patients attended two, and two patients attended three appointments, the rest making a single visit. Four hundred and twelve of the appointments were routine while 11 were patient-initiated 'interval' visits. Eleven possible recurrences (three later confirmed) were found at the 11 'interval' visits, while 19 possible recurrences (four later confirmed) were found at the 412 routine visits. Thus recurrences were detected at only $1 \%(4 / 412)$ of routine visits as compared with $27 \%(3 / 11)$ of 'interval' visits $\left[\chi^{2}\right.$ with Yates' correction $=30.8, P<10^{-5}, 1$ d.f.].

The initial treatment of the seven women with recurrent disease was by surgery alone in three cases and surgery with radiotherapy in four cases. 
Table II Potentially curative breast cancer treatments given to 402 women

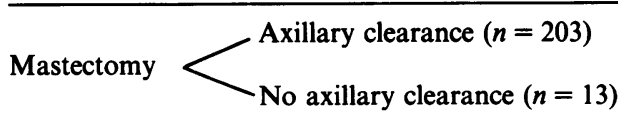

Wide excision $\underbrace{\text { Axillary clearance }(n=145)}_{\text {No axillary clearance }(n=41)}$

Adjuvant breast radiotherapy $(n=173)$

Adjuvant tamoxifen - post-menopausal patients

Adjuvant chemotherapy - pre-menopausal patients with 1-3 lymph nodes involved

Table III Tumour histology

\begin{tabular}{lr}
\hline Histological type & $\mathrm{n}(\%)$ \\
\hline Invasive ductal carcinoma & $312(78)$ \\
Invasive lobular carcinoma & $30(8)$ \\
In situ ductal carcinoma & $25(6)$ \\
Tubular carcinoma & $13(3)$ \\
Medullary carcinoma & $11(3)$ \\
In situ lobular carcinoma & $4(1)$ \\
Others & $4(1)$ \\
Unknown & $3(1)$ \\
\hline
\end{tabular}

Six patients had had a mastectomy, one a wide local excision and all seven, an axillary clearance. One pulmonary and two locoregional recurrences were detected at interval visits. One pulmonary, one bone and two locoregional recurrences were detected at routine visits.

Of the 402 patients, 285 were asked to complete the questionnaire and $223(78 \%)$ complied. The results are shown in Table I(b). Few had to take time off work $(22 \%)$ or make special domestic arrangements (12\%) to get to the clinic. Most used their own transport $(64 \%)$ and had to travel less than 6 miles. The majority had been taught to examine their breast area $(85 \%)$ and did so once a month or more $(74 \%)$. Most patients preferred the idea of hospital follow-up to general practitioner follow-up ( $76 \%$ ), and claimed to feel reassured and less anxious when they attended the clinic $(81 \%)$.

\section{Discussion}

After potentially curative treatment of breast cancer, patients are followed-up for three main reasons. One of these, audit, has not so far been mentioned in this paper. This is clearly important in a disease in which treatment failures remain $\mathbb{D}$ common. Whether out-patient follow-up is the only or best method for obtaining audit (or $\Rightarrow$ research) data will not be discussed further here. $\stackrel{(0)}{\mathcal{O}}$ We would suggest, however, that patients are unlikely to regard their clinic visits as being principally of value for audit or research!

Most doctors and patients regard the chief $\varnothing$ reason for follow-up to be the detection of recur- $\cong$ rent disease. The major point at issue is whether there is any benefit in such detection before the $?$ patient becomes symptomatic. What evidence $\vec{\omega}$ there is suggests that detection and treatment of $\stackrel{\circ}{\circ}$ asymptomatic disease results in no better survivalo than treatment of symptomatic recurrence. ${ }^{1,3,4}$ If 3 . this is so, detection of asymptomatic recurrence ${ }_{\infty}$ merely gives a patient more prolonged knowledge $\dot{0}$ of treatment failure without any ultimate thera- $O$. peutic benefit. It is clear from our results that $\varphi$ 'interval' appointments yield a far higher propor- + tion of recurrences than do routine follow-up을 appointments. This is in agreement with previous findings. ${ }^{2,5}$ The questionnaire results show that $z$ most patients examine their breast areas regularly ${ }_{\Phi}$ and frequently. On these considerations alone, there would seem to be good reasons for discon- $\underline{\text { D }}$ tinuing the practice of routine follow-up after $\vec{\theta}$ potentially curative treatment of breast cances. Women, however, prefer 'routine' to 'interva; appointments. They prefer conventional hospitâl follow-up to the idea of general practitioner followup which has been suggested by previous authors. ${ }^{6}$ The majority feel reassured and less anxious when they attend the clinic. In addition, only a few have $\varrho$ to take time off work or make special domestic $\overrightarrow{\hat{O}}$ arrangements to come to the clinic. Most women 3 have to travel only a short distance to the clinic and most do so using their own transport. Thus our? follow-up clinic appears to be popular and atten-क을 dance causes little inconvenience.

We have not asked women whether they expect follow-up to increase their chances of survival but-: the popularity of the follow-up clinic suggests that this is probably their expectation. Clearly, however, it would not be supportive to these patients 음 who are often distressed, to suggest that they may $D$ be able to follow the subsequent course of their? disease as effectively as the doctors in the clinic. N

The solution to this dilemma is not clear. $\mathrm{An}^{-}$ alternative to routine follow-up might be postoperative counselling with clinic visits only when $\tilde{N}$ requested by patients. A randomized trial comparing the value of routine and 'on demand' follow-upe in patients having potentially curative treatment $\Phi$ for breast cancer is probably timely. 


\section{References}

1. Dewar, J.A. \& Kerr, G.R. Value of routine follow up of women treated for early carcinoma of the breast. $\mathrm{Br}$ Med J 1985, 291: $1464-1467$.

2. Holli, K. \& Hakama, M. Effectiveness of routine and spontaneous follow-up visits for breast cancer. Eur J Cancer Clin Oncol 1989, 25: 251-254.

3. Stierer, M. \& Rosen, H.R. Influence of early diagnosis on prognosis of breast cancer. Cancer 1989, 64: 1128-1131.
4. Tomin, R. \& Donegan, W.L.. Screening for recurrent breast cancer - its effectiveness and prognostic value. J Clin Oncol 1987, 5: 62-67.

5. Tate, J.J.T., Clifford, P.C., Royle, G.T., Buchanan, R.B. \& Taylor, I. After surgery for breast cancer, which mode of surveillance? J R Soc Med 1989, 82: 737-738.

6. Clark, P.B. \& Morris, D.L. Management of patients after mastectomy. Br Med J 1981, 282: 2095-2096. 